\title{
Anonymity Effects and Implications in the Virtual Environment: From Crowd to Computer-Mediated Communication
}

\author{
Zuoming Wang \\ Department of Communication Studies, University of North Texas, Denton, TX, USA \\ Email: wangz@unt.edu
}

How to cite this paper: Wang, Z.M. (2018) Anonymity Effects and Implications in the Virtual Environment: From Crowd to Computer-Mediated Communication. Social Networking, 7, 45-62.

https://doi.org/10.4236/sn.2018.71004

Received: November 28, 2017

Accepted: January 9, 2018

Published: January 12, 2018

Copyright $\odot 2018$ by author and Scientific Research Publishing Inc. This work is licensed under the Creative Commons Attribution International License (CC BY 4.0).

http://creativecommons.org/licenses/by/4.0/

Open Access

\begin{abstract}
Anonymity, an important feature of computer-mediated communication (CMC), is embedded in this new technology. With the penetration of the Internet in society, many daily activities involve online interactions. Anonymity affects both the task and social aspects of online communication including information exchange, decision making, and relationship development. This review examines the effects of anonymity on human behavior. It outlines how the prior literature has attempted to address this issue and how the Social Identity Deindividuation (SIDE) model has developed as an attempt to tackle this question. More importantly, it discusses a framework describing the multidimensions of anonymity in CMC [1], and subsequently raised five propositions inspired by this framework. Furthermore, using McLeod's framework, this review evaluates SIDE studies with regard to their anonymity manipulations. This critique reveals possible future research directions for refining the SIDE model and better studying the effect of anonymity in virtual environment.
\end{abstract}

\section{Keywords}

Anonymity, Virtual Environment, Computer-Mediated Communication, SIDE

\section{Literature Review}

Anonymity, an important feature of computer-mediated communication (CMC), is embedded in this new technology. The internet community is quickly changing and evolving as more of the world comes on-line. Free speech and anonymity have always been important real-world societal issues. These issues are becoming increasingly important as more people discover the digital world and 
find the need for anonymity in this new society. The citizens of the net feel that anonymity is vital for the protection of freedom of expression. It is obvious that the technology for anonymity on the internet is readily. With the penetration of the Internet in society, many daily activities involve online interactions using email, list serves, instant messaging, chat rooms, bulletin boards, and video games. Anonymity, exemplified in those online activities, affects both the task and social aspects of online communication including information exchange, decision making, and relationship development.

Interest in the effects of anonymity on identity issues is growing fast with an increasing diversity of empirical studies. In particular, research on deindividuation and its application in the online environment using the Social Identity Model of Deindividuation (SIDE) [2] is influential and has started to snowball. However, given the fact that the definition and operationalization of anonymity are not agreed-upon among researchers, it poses a problem for generalizing across the results.

\subsection{Anonymity Studies: From Loss of Self in Crowd to Identity Switch}

This paper first provides a historical account of anonymity research. Early anonymity studies stem from the research on crowd behaviors. A crowd context alters the way in which people see themselves and their social world, as well as the ties that bind individuals [3]. As Reicher [4] summarized, "It frees them both from the ordinary relationships which bind them into social convention and also from the coercive power of authority. It therefore allows individuals to act upon their understandings even against the constraints of their opponents. In sum, the crowd provides both the inclination and the ability to act as a collective subject" (p.175). In other words, being an indistinguishable part of the mass leads to a mix of power without responsibility, which in turn makes crowd members act in uncontrolled ways.

Incorporating this idea of the crowd mind-set in early anonymity research, social psychologists developed deindividuation theory, which claims that immersion in a group, particularly operationalized in terms of lowered personal visibility, results in a loss of identity, as well as a loss of control. Once people become anonymous and submerge into the crowd, they lose their individuality, accountability, and personal identity, which often results in anti-social behaviors [4]. Therefore, the early account of anonymity is characterized by its focus on the loss of self by submerging into a collective mind and exhibiting the subsequent negative behavioral effects.

The early deindividuation research tends to regard anonymity as antecedent of deindividuation. Largely influenced by descriptions of crowd behavior, Festinger, Pepitone, and Newcomb [5] defined deindividuation as a state in which people are not seen or paid attention to as individuals in groups or other collectives. Zimbardo [6] further developed deindividuation into a full-fledged theory. He defined deindividuation as a complex, hypothesized process in which ante- 
cedent social conditions change the perception of self and others, thus lowering the threshold of normally restrained behavior such as violating norms. He further claimed that anonymity promotes deindividuation and decreases individual accountability, which in turn reduces the pressure for them to conform to social norms.

To explain how anonymity produces deindividuation, early deindividuation theory proposed that immersion and anonymity in the group could result in a "loss of self" or at least reduced self-awareness [5] [6] [7] [8]. Whether the "loss of self" identity actually occurs in anonymous conditions becomes the key that distinguishes another school of deindividuation researchers [9] who argue that anonymity in the group does not necessarily produce a loss of identity, but actually promotes a switch from individual identity to social identity and enhances the salience of group identities.

In addition to treating anonymity as a source of deindividuation, early deindividuation theorists suggested that anonymity has potentially negative effects on social behaviors such as disinhibition and attraction to deviant groups due to the loss of self and of self-control of individuals in the crowd. Correspondingly, early $\mathrm{CMC}$ research claims that due to deindividuation, online interactions are more likely to engage in hostile expression of strong emotions and feelings, called flaming [10]. However, the emergence of social identity theory (SIT) and selfcategorization theory (SCT) [11] [12] challenges these ideas, arguing that anonymity does not always lead to anti-normative behavior. Specifically, they state "a group is a set of people who share a common social identity and that, when acting in terms of social identity people seek to conform to that which characterizes category meaning"; therefore "people do not lose identity and hence lose control in the crowd. Rather they shift from personal to social identity and their behavior becomes shaped by the understandings that define the relevant social category" (p.176-177) [4].

Empirical studies challenge the assumed association between anonymity and negative behavior. For instance, anonymity was found to decrease transgression [6] and to lead to unpredictable results [7]. Diener, Dineen, and Westford [13] found that anonymity did not facilitate disinhibited behaviors in groups. Meanwhile, accumulated experimental evidence brings up the issue of communication context to people's attention when studying anonymity effects. For instance, Johnson and Downing [14] found that depending on what kind of cues given in the situation (positive vs. negative), anonymity can either prevent aggression or provoke it.

\subsection{Social Identity Model of De-Individuation Effect (SIDE)}

The SIDE approach is a distinctive and strong perspective in social psychology. SIDE has been proposed to describe, explain and understand both specific and general classes of phenomena of intra- and intergroup behavior [15] [16]. The SIDE model focuses on the way in which people think and behave in particular 
group situations. The situations in focus are described as "de-individuated" or "de-personalised" by previous theories of crowd behavior. Those situations are characterized by the limited perceptions of fellow group members (anonymity) or limited visibility of oneself to other group members (lack of identifiability) [17]. An instance of this type of situation is CMC [18].

Identity-who you are (as an individual or as a group member) - is the key issue of the SIDE model. SIDE clearly differentiates the personal/individual and social/group identity. It adopts a group-based approach and assumes that the salient membership in a group can be crucial in such situations, bringing people to define themselves, to present themselves, and/or to act as group members rather than as single individuals [17].

Social identity processes are considered responsible for the anonymity effects on groups in both face-to-face interactions and in CMC settings. One of the prominent effects of anonymity in CMC is that there are fewer perceived intragroup differences in the group [18]. "According to SIDE, the relative anonymity associated with mediated communication is crucial for predicting and understanding behaviour in the new computer medium" (p. 48) [19]. In this regard, anonymity enhances the salience of group identity and consequently stimulates group-related behavior [2]. More specifically, visual anonymity, which is greatest in remote text-based CMC (relative to normal face-to-face interaction) tends to depersonalize perceptions of self and others and encourages behavior that is normative for salient groups [16].

Indeed, a growing body of empirical evidence supports that anonymity in the group strengthens rather than weakens social influence. For example, Spears, Lea, and Lee [18] found that when group members were isolated and anonymous during interaction, their attitudes toward discussion topics that were salient for the interacting group polarized more in the direction of pre-existing group norms than when members were identifiable and co-present. Similarly, in a CMC study conducted between groups composed of different nationalities, anonymity was found to increase group members' conformity to ingroup norms and rejection of outgroup norms [20]. Further studies that directly manipulated the salience of particular group norms found anonymity increases adherence to whatever norm was primed in groups with whom participants identified [21].

Anonymity, which triggers deindividuation, is the basis of SIDE effects. There are two important dimensions of SIDE model: cognitive and strategic dimensions [22], which correspond to different types of anonymity. Specifically, the cognitive dimension of SIDE refers to how some classic deindividuation effects of anonymity in the group can affect self-definition by influencing the salience of group identity in particular [18]. Much of the empirical work in this line concentrates on how anonymity affects self-categorization and social influence in CMC. The SIDE model proposes that its cognitive dimension is driven by anonymity of others to self (defined as limited perceptions of fellow group members) influencing the salience of the category. On the other hand, the strategic dimension of SIDE deals with the expression of normative behavior, which was 
found to be affected by identifiability [23] [24] [25]. This dimension of SIDE is related more to anonymity of self to others (defined as limited visibility of oneself to other group members). An alternative way to describe this distinction between anonymity of others to self and anonymity of self to others was introduced by Sassenberg [26] who labeled the former as "the anonymity of sources (identifiability)" and the latter as "the anonymity of targets (anonymity)." $\mathrm{He}$ pointed out that research until now has tended to focus on either one of them, instead of taking both factors into account simultaneously.

To better understand SIDE, we should separate the cognitive/self-definitional aspect of SIDE from the strategic/self-presentational aspect of SIDE. However, we should also be aware that these two dimensions may not be independent and additive, they may interact. For example, anonymity of self to others (the cognitive component) may also increase the salience of the group by merging self with the group identity [27]. Meanwhile, the anonymity of self to others can also impinge on the cognitive aspect of SIDE [19]. That is, the strategic dimension might feed into the processes of self-definition [16]. Therefore, Douglas and McGarty [28] suggest that these two factors can not be treated as independent from one another, because their impacts on group salience and group norms may interact.

Given the two types of anonymity associated with two dimensions of SIDE, one important question it evokes is what kind of the social identification processes would occur when the anonymity is asymmetrical within the group. Lea, Spears, Watt and Rogers [19] predicted that "anonymity of self to others should directly increase depersonalized self-perception, while anonymity of others should primarily increase perceptions of group homogeneity, of the group as an entity, and the tendency to stereotype others in terms of the group" (p. 51). To support their arguments, they conducted an experiment using 3-person groups ( 1 participant, 2 confederates). The experiment was designed to separate visual anonymity of the self to others from visual anonymity of others to the self (with a control group under complete visual anonymity of self and others). Groups communicated in one of three conditions: participant sends video to others (but does not receive video); participants receive video from others (but does not send video); participant sends and receives no video. In all three conditions the group communicated by multi-way text conferencing, in addition to any video. The preliminary results suggest rather complex effects occur when anonymity is asymmetrical within the group. They found that visibility of others increased the participants' sense that they could recognize and identify the others. However, identifiability of others had no direct effect on stereotyping of others. Instead the effect of visibility of others, when the self is anonymous, appeared to activate several different processes. Firstly, identifiability of others directly increased group attraction. This effect occurred independently of depersonalization processes. Secondly, identifiability of others increased self-categorization, which in turn increased group attraction; and self-categorization increased stereotyping of 
others, which also increased group attraction" [19]. They summed up three processes occurring in the study: first, an interpersonal attraction process increased by visibility of others; a second social identity-based depersonalized attraction process increased by visible common gender cues; and a weaker third comparative process in which identifiability of others coupled with anonymity of self causes the separation of the self from the group. By separating the cognitive component of social identity (self-categorization) from one of its affective components (attraction to the group), Lea et al. [19] suggested that visual anonymity achieves its effects on social identification primarily by influencing the cognitive component of self-categorization with the group. Based on this rationale and the two aspects of anonymity reviewed before, one proposition is raised:

Proposition 1: In the "others to self" anonymous condition, participants experience higher levels of self-categorization with the group, and subsequently achieve higher level of group attraction than in the "self to others" anonymous condition.

\section{Method}

\subsection{Using McLeod's Comprehensive Model of Anonymity in CMC to Examine the Extant Literature}

As discussed before, anonymity is the basis for the SIDE effect to occur. Therefore, the conceptualization and operationalization of anonymity is important at both methodological and theoretical level. The most comprehensive model of anonymity in CMC so far was advanced by McLeod [1]. She not only presented a thorough overview of the anonymity effect studies on decision making in computer-supported groups, but also identified the several empirical problems in the prior literature on anonymity.

Firstly, research on anonymity has focused primarily on the idea generation aspect of group decision-making, and to a large extent, ignored the information exchange, consensus reaching, and choice-making aspects of group decision making [29] [30]; Secondly, differences in technologies, tasks, and experimental paradigms employed by different researchers make it difficult to generalize across the results [31]. Moreover, the operationalizations of anonymity vary widely among researchers [32] [33]. In sum, "the effects of anonymity on decision making in computer-supported groups remains poorly understood" (p. 224) [1]. This to a large extent should be attributed to the lack of a clear definition of anonymity that researchers agree upon.

Echoing this viewpoint, Barreto and Ellemers [34] stated that anonymity is not an absolute concept, but instead has a comparative connotation. As a result, it is possible to find considerable variations in what has been regarded as anonymous circumstances. For instance, in a few studies, anonymity was operationalized as lack of accountability pressure [34] [35] [36]. Others [37] measured anonymity by whether or not co-present participants were required to state their responses aloud. Here anonymity was regarded as the privacy of responses. 
Moreover, anonymity can also be considered as whether or not participants could see each other [18].

Based on the previous empirical works [33], McLeod [1] introduced a comprehensive model of anonymity in computer-supported group decision making, breaking down anonymity into three dimensions.

The first dimension deals with the mechanisms that trigger anonymity. It involves two aspects: technical and social anonymity. Technical anonymity refers to the mechanical practices used to dissociate individuals from their inputs. The practices include suppressing real names and physically isolating participants in different locations. On one hand, technical anonymity affects participants' ability to attribute specific messages to specific sources. For instance, it can yield content anonymity in which group members can identify the source of a message based on an identifier embedded in the interaction. On the other hand, technical anonymity can also affects process anonymity in which group members can determine who is participating by directly observing who is making a contribution. Social anonymity refers to individuals' subjective experience of anonymity-whether they believe they are anonymous and others are anonymous to them. This social dimension of anonymity can be further categorized into two types: social dissociation and identitylessness. The former refers to a feeling that others cannot identify one as the source of specific messages, while the latter is associated with feeling that others don't know that one is a participant or what one's role in a session might be [1].

Features of these two dimensions of anonymity and the relationship between them are also discussed. Technical anonymity is fixed once established, while social anonymity is more volatile, depending on numerous aspects of the communication situation such as the nature of the relationships among the communicants, the number of communicants, the information exchange requirements of the task, and the amount of time the communicants spend together [1]. Moreover, these two types of anonymity do not necessarily match each other, as the social anonymity can be low, even when technical anonymity is high [33]. McLeod [1] noted although most of the anonymity studies provided details about the technology they used, revealing a high level of technical anonymity achieved in those studies overall, not all of them reported the participants' subjective feeling of anonymity. Thus, assuming social anonymity is achieved when technical anonymity is established may be a fallacy in the extant literature.

The second dimension of McLeod's model is concerned with the domain of anonymity. This can be characterized as message source and participant presence. The message source category refers to the ability to attribute specific messages to a specific source. The participant presence category refers to knowledge about the presence of other group members, including knowing whether a particular individual is a member, knowing general characteristics of the other group members, and knowing how much any one group member participants [1]. 
The third dimension of this comprehensive anonymity model deals with the perspective of anonymity, in other words, the direction of anonymity: self-toothers anonymity versus others-to-self anonymity [16]. The former refers to an individual's ability to identify or make attributions about the other members in the group, while the latter refers to the ability of others to identify or make attributions about that individual.

Examining these three dimensions of anonymity, McLeod [1] further pointed out that they are often very closely related. For instance, the social and technical aspects of anonymity may influence the degrees of anonymity from the self to others, or from others to the self. Content anonymity represents anonymity in the direction of self-to-others as it refers to individuals' ability to identify the source of a message based on available identifiers. Process anonymity also goes in the direction of self-to-others, as it represents individuals' ability to determine who is participating based on direct observation of the interaction. In comparison, source disassociation represents others-to-self anonymity since in this situation others may or may not identify one as the source of specific messages. And identitylessness also goes in the direction others-to-self direction of anonymity, since it represents others' ability to tell whether one is a participant and that individual's role in the interaction [1].

Besides specifying the three dimensions of anonymity in CMC, McLeod's model of anonymity also introduces a temporal aspect of anonymity in CMC. This temporal effect is coupled primarily with the social dimension of anonymity. She argued that anonymity, specifically along the social dimension, would be lower within groups of previously acquainted people than within ad hoc groups. That is, the group history such as the degree of acquaintance among the members may affect the degree of social anonymity. Taking this perspective, the extant literature on anonymity effects is re-examined. Results reveal many SIDE studies, all of which incorporating the anonymity component, tend to use ad hoc groups and do not involve the real interactions. For instance, some studies used mere exposure like presentation of the group members' arguments [17], or the predetermined script from confederates [19], or pre-programmed arguments automatically generated by computers [38] [39].

McLeod [1] acknowledges the importance of the degree of acquaintance among the group members, which can be largely influenced by the amount of time that members have for engaging in the real interactions with each other. Indeed, as members participate together in anonymous discussions over time, the degree of anonymity they perceived to exist among them may change [40] [41]. The establishment of "online self" and impression formation of others could occur through reciprocal interactions and other cues such as pseudonyms. Therefore, despite the fact that technical anonymity may still remain high, social anonymity could gradually go low. Combining this rationale with the anonymity's effect on deindividuation reviewed before, it is reasonable to extend McLeod's proposition and postulate the following prediction: 
Proposition 2: Anonymous members in CMC groups should feel less deindividuated due to the decrease of social anonymity over time.

Moreover, not all anonymity effect studies include the manipulation of nominal identity (by the use of real names, or group member identifiers) as part of the main anonymity manipulation [15]. Lea, Spears, Watt and Rogers [19] claim that nominal anonymity provides a strategic effect on perceptions of accountability within the group relative to conditions where group members are identified by name. They argue that "knowing the names of one's co-communicators, and knowing that one's own name is also known within a closed environment where future interaction is possible and indeed inevitable is sufficient to realize the consequences of accountability" (p. 54). This is most likely to be true given the fact that many CMC experiments used student samples that are from the same university or even the same department. First of all, anonymity is supposed to protect people from the accountability to powerful outgroups, allowing free expression of group identity [42] [43]; while accountability is associated with the concern of self-presentation, and visibility of participants to each other is likely to be associated with greater focus on interpersonal differences, both undermine the deindividuation process. Moreover, accountability is the key for compliance to the group norms under this circumstance, and anonymity is supposed to reduce perceptions of strategic accountability within the group, which in turn reduces group conformity. Therefore, based upon these rationales, another proposition is raised:

Proposition 3: In the nominal anonymous condition, participants should perceive lower accountability and are less likely to conform to the group norms than those in nominal identifiable condition.

Furthermore, Lea and his colleagues [19] indicated that "visual anonymity has been demonstrated to be a powerful situational factor that depersonalizes perceptions of self and others by eliminating communication of physical and nonverbal cues. However, nominal anonymity may also reduce self-perceptions of unique individuality and activate social identity processes in a salient group" (p.54). That is, the anonymity effects on self-categorization may not limited to visual anonymity. These two sides of anonymity together may produce an amplified effect of depersonalization in the group, especially when the group identity is salient. Based on these rationales, the following propositions are raised:

Proposition 4: When the group identity is salient, participants who are both visually and nominally anonymous should achieve the highest level of deindividuation; participants who are both visually and nominally identifiable should reach the lowest level of deindividuation; the deindividuation level of participants who are either visually or nominally anonymous should fall in between.

As reviewed before, when group identity is salient, anonymity may obscure intragroup differences and accentuate the salience of group identity; while if personal identity is salient, anonymity is supposed to foster behavior that fulfills the need for individual distinctiveness. Therefore, another proposition is ad- 
vanced:

Proposition 5: When the individual identity is salient, participants who are both visually and nominally anonymous should feel more individuated than participants who are either visually or nominally anonymous.

The above five propositions inspired by McLeod's (1997) are based on the relevant theories on anonymity and pose important research direction for scholars who investigate the effect of anonymity. They are subject to further empirical studies to examine their correctness. This article is the first step as it lays out these propositions, and future research (which is beyond the scope of this article) needs to be conducted to empirically test those propositions.

\subsection{Examining Anonymity Manipulation in SIDE Using McLeod's Model}

Classic anonymity manipulation: Before going into the details of anonymity manipulations in SIDE studies, it is important to revisit how classic theorists did it. Zimbardo [6], who laid the foundation for deindividuation research, identified anonymity as the key factor that leads to deindividuation, and also regarded it as the operationalization of deindividuation. His manipulation of anonymity was obscuring the physical features of the participants (e.g., use large coats and a hood over the head), eliminating the nominal cues (e.g., prevent the use of personal names), and blurring the environment (e.g., turn the lights off).

Derived from Zimbardo's influential works, the classic anonymity manipulation is usually achieved by dressing people in masks and overalls (versus leaving them identifiable in their normal clothing). The essence of this manipulation lies in its effect on identities. It would accentuate the effects of group identity by reinforcing group distinctions when group identity was already salient (i.e. by eliminating a focus on interpersonal difference), but not when individual identity was high (where group boundaries were not distinguishable in any case). An alternative way of manipulating anonymity was the physical isolation and thus lack of visibility of others. For instance, Spears, Lea, and Lee [18] conducted a study using psychology students as participants, where participants were either isolated in 3 separate rooms, or were located in the same room and visible to each other.

Current issue about anonymity in SIDE: Anonymity is not a monolithic concept. Central problems remain unsolved in the anonymity literature include which form(s) of anonymity is examined in SIDE, whether different forms of anonymity may activate the same processes, or whether different anonymity forms activate cognitive and strategic processes to different extents, which in turn produce various behavioral effects. Lea, Spears, Watt, and Rogers [19] noted that "Different types of anonymity should be distinguished, such as visual anonymity (lacking physical nonverbal cues to the self), nominal anonymity (lacking a name or personal identifier), biographical anonymity (lacking details of self), or domiciliary anonymity (lacking a traceable address). These different forms of anonymity may have similar or different effects, and some forms may 
have additional effects over others, which crucially depend upon contextual conditions, as well as intra- versus inter-group contexts" (p. 59). Failing to address these problems makes it increasingly difficult to maintain the boundary of SIDE effects.

Using McLeod's framework to examine SIDE: McLeod's [1] comprehensive model of anonymity draws a holistic picture of anonymity. Although this model is derived primarily from the research on online decision-making, many of its ideas, especially its classification of anonymity and description of the manipulation, could benefit the contemporary SIDE studies to a large extent. Taking the perspective of McLeod's framework, this review proceeds to evaluate the extant literature on the SIDE model.

On the mechanism dimension of anonymity, most of the SIDE studies have reported how they manipulate technical anonymity (i.e. what kind of mechanical practice was used to dissociate individuals from their inputs), while leaving out the social anonymity. Very few of the studies has conducted manipulation checks to ask participants whether they are unsure that others in the group or outside of the group could attribute their comments to them. Instead technical anonymity is widely used as the proxy of social anonymity in most SIDE studies. This could be problematic as McLeod indicated that these two aspects may not parallel to each other. Social anonymity could be low while technical anonymity is high.

With regard to manipulation of technical anonymity, SIDE studies show variety. In principle, technical anonymity is highly influenced by the presentation of visual information by displaying vs. not displaying pictures [21] [44] or biographical information of all ingroup members to the participants [45], or the co-presence in the same location of all participants (hence visible to each other).

For studies conducted online, an identifier (either a number, or a letter, or a cartoon) is usually used to suppress real names (with the exception of Lea, Spears, \& De Groot [27]). However, some studies further physically separate participants [38] [39] in different rooms, while others have a mixed condition. For example, Lea and Spears [15] (experiment 2) gave each subject a number as identifier, and then assigned subjects to either of the two conditions. The first condition placed subjects to separate rooms and physically isolated them from each other throughout the experiment, the other condition seated subjects at separated desks two or three meters apart in the same room to use the computer-conference system. In this condition, subjects faced each other throughout the experiment, but were not allowed to talk to each other. In this particular study, the suppression of real name partially achieved the technical anonymity. However, the different ways of placing subjects introduced a possible confound to the anonymity effect in this study.

For SIDE studies conducted in face-to-face setting, manipulation of technical anonymity is sometimes crossed with the manipulation of identity. For instance, Reicher, Spears, and Postmes [2] manipulated technical anonymity in which subjects, each assigned a number, were either dressed normally (identifiable) or 
in baggy overalls and masks (anonymous). However, this manipulation was confounded, again, by the seating of subjects. In one condition, subjects were seated at separated tables in the same room, while in the other condition subjects were mixed together and sat in rows facing the front of the lab. In sum, the level of technical anonymity varies widely in SIDE studies conducted both online and offline, not to mention the social anonymity which is usually assumed rather than tested in those studies.

On the domain dimension of anonymity (message source and participant presence), the situations are also complicated. Even when technical anonymity is held constant, message source anonymity could vary within one experiment. For instance, in each of the two experiments conducted by Lee [38], two types of visual presentation of participants were used. One condition used different cartoon characters to represent participants; the other condition used the same cartoon character to represent subjects. Therefore the level of message source anonymity (the ability to attribute specific messages to a specific source) was different in the study. It was much easier to attribute a specific message to its source in the different cartoon character condition although all participants were still visually anonymous.

With regard to participant presence, SIDE studies conducted in CMC tend to have low anonymity on that, because once subjects start participating in the online interactions, it is easy to figure out the number of group members. Meanwhile, since the computer system automatically records the inputs from each participant and displays them on screen, it is easy to know how much any one group member participates. Moreover, in many SIDE studies using college students [38] [39] [45], participants knew that their group members were also college students coming from either the same or a different institution. However, having said that, there is one aspect of participant presence which is hard to gauge. That is, it is usually hard to know whether a particular individual is a member without further information, even though participants may know which school this person is from.

On the perspective dimension of anonymity, the SIDE studies often encounter the problem of activating both "self to others" anonymity and "others to self" anonymity simultaneously. For example, participants not only saw pictures or individuating information about the ingroup members or not (a manipulation of anonymity of "others to self"), but also were under the impression that other group members had the same information about them (a manipulation of anonymity of "self to others") [44] [45]. Therefore, the experimental investigations of SIDE model have tended to confound these two types of anonymity. Another issue worth noting is that many SIDE studies [15] [38] [39] did not involve real interactions among group members, including Lee's studies using 3-person groups with one real subject and two ostensible partners. In this regard, the direction of anonymity was asymmetrical. The self-to-others anonymity could be accessed, while others-to-self anonymity could not be traced simply because the 
ostensible partners would not count as real participants and there were no data collected from them, either.

Taken together, a close examination of how anonymity is manipulated in SIDE studies has shown huge differences in McLeod's comprehensive model of anonymity in CMC and the SIDE studies. The former has specified, besides three dimensions, several concrete aspects of communicative factors including the physical arrangement of group members that influence the anonymity manipulation. Those aspects are more or less neglected in the SIDE studies. Instead SIDE research tends to treat anonymity as an abstract concept rather than a multifaceted variable. Visual anonymity is the predominant form of anonymity manipulated in SIDE studies. As a result, use of identifiers such as pseudonyms (i.e., cartoon, number, and letter) to represent group members is widely accepted and considered sufficient in SIDE studies to ensure the ingroup homogeneity and deindividuate members in CMC interactions. However, based on the standards proposed in McLeod's framework, it is questionable whether anonymity is really achieved that way. Moreover, compared to traditional anonymity studies, SIDE research exhibits a more complicated pattern with regard to its anonymity manipulations. For instance, traditional anonymity research tends to achieve a relatively stable level of technical anonymity, while technical anonymity could vary within one experiment as shown in SIDE literature. Moreover, the SIDE focuses on "who are you online?" Whether people are perceived as individuals or as group members is what SIDE model strikes to answer. Given the importance of identity issues in SIDE, some studies try to ensure the activation of individual vs. group identity while sacrificing a clear-cut anonymity manipulation. Based on the McLeod's framework on anonymity, SIDE studies could improve through the direct manipulation of anonymity on at least three aspects: mechanism, domain, and perspective. Therefore, it is reasonable to speculate that if all dimensions of anonymity are achieved through direct manipulation, the deindividuation effect may be accentuated and a more prominent SIDE effect could be observed.

\section{Results \& Discussion}

The main problem the paper aims to tackle is to challenge the traditional approach of studying anonymity and point out its inconsistent ways of conceptualizing and operationalizing anonymity. In that, it tries to use McLeod's (1997) view on anonymity to decompose anonymity into three dimensions and theoretically construct a comprehensive approach to examine anonymity. Specifically, this review takes a two-fold approach in the examination of anonymity in CMC. On one hand, it imports constructs and ideas from the classic deindividuation research into the empirical works in CMC and addresses how anonymity effect research goes across the context boundary. On the other hand, it investigates how an online setting helps researchers better understand anonymity and identity issues. Anonymity here is explored as a means to understand the fun- 
damentals of human behavior.

Anonymity effects research can be traced back to crowd behavior studies. Its application, in particular, the SIDE, has been widely tested in the CMC context. The early account of deindividuation theory claims that anonymity promotes negative anti-social behaviors. Empirical research later reveals that it is not always the case. Anonymity can also produce positive effects and promote prosocial behaviors. Similarly, early CMC studies focus on the negative expression of emotions online (flaming effects) presumably instilled by anonymity. Researchers later found that flaming is not prevalent in online interactions, and anonymity actually reduces the interpersonal differences within groups and reinforces group salience, which in turn promotes conformity to the group norms. Identity and its transformation are the underlying mechanisms that drive these processes. Classic deindividution theory assumes that once individuals become anonymous and submerge into the group, they lose their individual identity as well as self-awareness. However, SIDE proposes that anonymity facilitates deindividuation that involves a switch of individual identity to a group identity, instead of the loss of the individuality.

CMC provides a new paradigm for research that can usefully clarify some of the complexities in anonymity effect research. For example, it makes it possible to separate the cognitive and strategic aspects of anonymity, and directly observe the effects of "others to self" anonymity and "self to others" anonymity. Along this line, another point for consideration is the close relationship between the development of SIDE and its primary domain of investigation, CMC. Through studying SIDE, researchers can develop general principles of group behavior that can be applied to specific contexts such as CMC, or public crowds, and measure the extent to which these general principles hold in these specific domains.

\section{Limitation \& Future Research}

Inspired by a comprehensive model of anonymity in CMC proposed by McLeod [1], which breaks down anonymity into three dimensions: mechanism, domain, and perspective, five propositions have been raised in this review. Although the theoretical classification is very important for tackling the current inconsistency in the anonymity literature, this paper does not provide any empirical test of the five propositions. Meanwhile, the classic studies on anonymity reviewed in this paper need to be expanded to the larger spectrum of nowadays Internet world, particularly the realm of social media.

Moreover, using McLeod's framework, this review evaluates SIDE studies and reveals that the anonymity manipulation in SIDE not only varies widely but also faces the challenge of possible confounds. Acknowledging this may help resolve some of the inconsistency that has been noted in the emerging literature on SIDE. The problems indicate some ways forward for future research. Clearly, more efforts are needed for documenting the discrepancy in the operationalization of anonymity in SIDE studies. Possible future research directly manipulat- 
ing anonymity from the three aspects identified in McLeod's framework would enable researchers to observe whether the deindividuation effect becomes more prominent when anonymity is fully achieved.

\section{References}

[1] McLeod, P.L. (1997) A Comprehensive Model of Anonymity in Computer-Supported group Decision Making. The 18th International Conference on Information Systems, Atlanta.

[2] Reicher, S.D., Spears, R. and Postmes, T. (1995) A Social Identity Model of Deindividuation Phenomena. European Review of Social Psychology, 6, 161-198. https://doi.org/10.1080/14792779443000049

[3] Le Bon, G. (1895) The Crowd: A Study of the Popular Mind. Transaction, London.

[4] Reicher, S.D. (2000) Social Identity Definition and Enactment: A Broad SIDE against Irrationalism and Relativism. In: Postmes, T., Lea, M., Spears, R. and Reicher, S., Eds., SIDE Issues Centre Stage: Recent Developments in Studies of De-Individuation in Groups, KNAW, Amsterdam, 175-190.

[5] Festinger, L., Pepitone, A. and Newcomb, T. (1952) Some Consequences of De-Individuation in a Group. Journal of Abnormal and Social Psychology, 47, 382389. https://doi.org/10.1037/h0057906

[6] Zimbardo, P.G. (1969) The Human Choice: Individuation Reason and Order versus Deindividuation Impulse and Chaos. In: Arnold, W.J. and Devine, D., Eds., $\mathrm{Ne}$ braska Symposium on Motivation, Vol. 17, University of Nebraska Press, Lincoln, 237-307.

[7] Diener, E. (1980) Deindividuation: The Absence of Self-Awareness and Self-Regulation in Group Members. In: Paulus, P.B., Ed., Psychology of Group Influence, L. Erlbaum, Hillsdale, 209-242.

[8] Prentice-Dunn, S. and Rogers, R.W. (1982) Deindividuation and the Self-Regulation of Behavior. In: Paulus, P.B., Ed., The Psychology of Group Influence, 2nd Edition, Erlbaum, Hillsdale, 86-109.

[9] Reicher, S.D. (1984) Social Influence in the Crowd: Attitudinal and Behavioural Effects of Deindivudation in Conditions of High and Low Group Salience. British Journal of Social Psychology, 23, 341-350. https://doi.org/10.1111/j.2044-8309.1984.tb00650.x

[10] Lea, M., O'Shea, T., Fung, P. and Spears, R. (1992) Flaming in Computer-Mediated Communication: Observations, Explanations, Implications. In: Lea, M., Ed., Contexts of Computer-Mediated Communication, Harvester-Wheatsheaf, London, 89112.

[11] Tajfel, H. (1978) Differentiation between Social Groups. Wiley, New York.

[12] Turner, J.C. (1982) Towards a Cognitive Redefinition of the Social Group. In: Tajfel, H., Ed., Social Identity and Intergroup Relations, Cambridge University Press, Cambridge.

[13] Diener, E., Dineen, J. and Westford, K. (1974) Correlates of Deindividuation in College Campus Crowds. Unpublished Manuscript, University of Washington.

[14] Johnson, R.D. and Downing, L.L. (1979) Deindividuation and the Valence of Cues: Effects on Prosocial and Antisocial Behavior. Journal of Personality and Social Psychology, 34, 1532-1538. https://doi.org/10.1037/0022-3514.37.9.1532

[15] Lea, M. and Spears, R. (1991) Computer-Mediated Communication, Deindividuation and Group Decision-Making. International Journal of Man-Machine Studies, 
34, 283-301. https://doi.org/10.1016/0020-7373(91)90045-9

[16] Spears, R. and Lea, M. (1994) Panacea or Panopticon? The Hidden Power of Computer-Mediated Communication. Communication Research, 21, 327-459. https://doi.org/10.1177/009365094021004001

[17] Waldzus, S. and Schubert, T. (2000) Group Norm and Category Norm in Anonymous Situations: Two Sources of Social Influence. In: Postmes, T., Lea, M., Spears, R. and Reicher, S., Eds., SIDE Issues Centre Stage: Recent Developments in Studies of De-Individuation in Groups, KNAW, Amsterdam, 31-45.

[18] Spears, R., Lea, M. and Lee, S. (1990) De-Individuation and Group Polarization in Computer-Mediated Communication. British Journal of Social Psychology, 29, 121-134. https://doi.org/10.1111/j.2044-8309.1990.tb00893.x

[19] Lea, M., Spears, R., Watt, S.E. and Rogers, P. (2000) The InSIDE Story: Social Psychological Processes Affecting On-Line Groups. In: Postmes, T., Lea, M., Spears, R. and Reicher, S., Eds., SIDE Issues Centre Stage: Recent Developments in Studies of De-Individuation in Groups, KNAW, Amsterdam, 47-62.

[20] Postmes, T., Lea, M., Spears, R., Croft, R., van Dijk, L. and van der Pligt, J. (1995) Bi-Polarization in Intergroup Negotiations: The Influence of Social Norms on Attitudes. In: de Veries, N.K., de Dreu, C.K.W., Ellemers, N. and Vonk, R., Eds., Fundamental Social Psychology, Tilburg University Press, Tilburg, Vol. 9, 1-24.

[21] Postmes, T., Spears, R., Sakhel, K. and De Groot, D. (2001) Social Influence in Computer-Mediated Groups: The Effects of Anonymity on Social Behavior. Personality and Social Psychology Bulletin, 27, 1243-1254. https://doi.org/10.1177/01461672012710001

[22] Reicher, S.D. (1982) The Determination of Collective Behaviour. In: Tajfel, H., Ed., Social Identity and Intergroup Relations, Cambridge University Press, Cambridge, 41-83.

[23] Reicher, S.D. (1987) Crowd Behaviour as Social Action. In: Turner, J.C., Hogg, M.A., Oakes, P.J., Reicher, S.D. and Wetherell, M.S., Eds., Rediscovering the Social Group: A Self-Categorization Theory, Blackwell, Oxford, 171-202.

[24] Reicher, S.D. and Levine, M. (1994) De-Individuation, Power Relations between Groups and the Expression of Social Identity: The Effects of Visibility to the Out-Group. British Journal of Social Psychology, 33, 145-163. https://doi.org/10.1111/j.2044-8309.1994.tb01015.x

[25] Reicher, S.D. and Levine, M. (1994) On the Consequences of Deindividuations for the Strategic Communication of Self: Identifiability and the Presentation of Social Identity. European Journal of Social Psychology, 24, 511-542.

https://doi.org/10.1002/ejsp.2420240408

[26] Sassenberg, K. (2000) The Two Faces of Anonymity: Effects on Groups Decision Making. In: Postmes, T., Lea, M., Spears, R. and Reicher, S., Eds., SIDE Issues Centre Stage: Recent Developments in Studies of De-Individuation in Groups, KNAW, Amsterdam, 93-106.

[27] Lea, M., Spears, R. and De Groot, D. (2001) Knowing Me, Knowing You: Effects of Visual Anonymity on Self-Categorization, Stereotyping and Attraction in Computer-Mediated Groups. Personality and Social Psychology Bulletin, 27, 526-537. https://doi.org/10.1177/0146167201275002

[28] Douglas, K. and McGarty, C. (2000) Another SIDE of CMC: Identitifiability and Strategic Behaviour. In: Postmes, T., Lea, M., Spears, R. and Reicher, S., Eds., SIDE Issues Centre Stage: Recent Developments in Studies of De-Individuation in Groups, KNAW, Amsterdam, 107-115. 
[29] Dennis, A.R. (1996) Information Exchange and Use in Small Group Decision Making. Small Group Research, 27, 532-550. https://doi.org/10.1177/1046496496274003

[30] Weisband, S.P. (1994) Overcoming Social Awareness in Computer-Supported Groups: Does Anonymity Really Help? Computer Supported Cooperative Work, 2, 285-297. https://doi.org/10.1007/BF00805695

[31] Hollingshead, A.B. and McGrath, J.E. (1995) Computer-Assisted Groups: A Critical Review of the Empirical Research. In: Guzzon, R.A. and Salas, E., Eds., Team Decisions and Team Performance in Organizations, Jossey-Bass, San Francisco, 46-78.

[32] Valacich, J.S., Jessup, L.M., Dennis, A.R. and Nunamaker, J.F. (1992) A Conceptual Framework of Anonymity in Group Support Systems. Group Decision and Negotiation, 1, 219-241. https://doi.org/10.1007/BF00126264

[33] Haynes, S.C., Rice, R. and Licker, P.S. (1992) Social Cues and Anonymous Group Interaction Using Group Support Systems. In: Proceedings of the Twenty-Seventh Annual Hawaii International Conference on System Sciences, IEEE Computer Society Press, Los Alamitos.

[34] Barreto, M. and Ellemers, N. (2000) You Can't Always Get What You Want: Social Identity and Self-Presentational Determinants of the Choice to Work for a Low Status Group. Personality and Social Psychology Bulletin, 26, 891-906. https://doi.org/10.1177/01461672002610001

[35] Batson, C.D., Ahmad, N., Yin, J., Bedell, S.J., Johnson, J.W., Templin, C.M. and Whiteside, A. (1999) Two Threats to the Common Good: Self-Interested Egoism and Empathy-Induced Altruism. Personality and Social Psychology Bulletin, 25, 3-16. https://doi.org/10.1177/0146167299025001001

[36] Noel, J.G., Wann, D.L. and Branscombe, N.R. (1995) Peripheral Ingroup Membership Status and Public Negativity toward Outgroups. Journal of Personality and Social Psychology, 68, 127-137. https://doi.org/10.1037/0022-3514.68.1.127

[37] Abrams, D., Wetherell, M., Cochrane, S., Hogg, M. and Turner, J.C. (1990) Knowing What to Think by Knowing Who You Are: Self-Categorization and the Nature of Norm Formation, Conformity and Group Polarization. British Journal of Social Psychology, 29, 97-119. https://doi.org/10.1111/j.2044-8309.1990.tb00892.x

[38] Lee, E.J. (2004) Effects of Visual Representation on Social Influence in Computer-Mediated Communication. Human Communication Research, 30, 234-259.

[39] Lee, E.J. (2005) Effects of the Influence Agent's Sex and Self-Confidence on Informational Social Influence in Computer-Mediated Communication: Quantitative versus Verbal Presentation. Communication Research, 32, 29-58. https://doi.org/10.1177/0093650204271398

[40] Walther, J.B. (1993) Impression Development in Computer-Mediated Interaction. Western Journal of Communication, 57, 381-398. https://doi.org/10.1080/10570319309374463

[41] Walther, J.B. (1994) Anticipated Ongoing Interaction versus Channel Effects on Relational Communication in Computer-Mediated Interaction. Human Communication Research, 20, 473-501. https://doi.org/10.1111/j.1468-2958.1994.tb00332.x

[42] Kielser, S., Siegel, J. and McGuire, T.W. (1984) Social Psychological Aspects of Computer-Mediated Communication. American Psychologist, 39, 1123-1134. https://doi.org/10.1037/0003-066X.39.10.1123

[43] Kiesler, S. and Sproull, L. (1992) Group Decision Making and Communication Technology. Organizational Behavior and Human Decision Processes, 52, 96-123. https://doi.org/10.1016/0749-5978(92)90047-B

[44] Postmes, T. and Spears, R. (1998) Deindividuation and Anti-Normative Behavior: A 
Meta-Analysis. Psychological Bulletin, 123, 238-259.

https://doi.org/10.1037/0033-2909.123.3.238

[45] Postmes, T. and Spears, R. (2000) Refining the Cognitive Redefinition of the Group: Deindividuation Effects in Common Bond vs. Common Identity Groups. In: Postmes, T., Lea, M., Spears, R. and Reicher, S., Eds., SIDE Issues Centre Stage: Recent Developments in Studies of De-Individuation in Groups, KNAW, Amsterdam, 63-77. 